\title{
A pilot project of glaucoma in Barbados
}

\section{CRISTINA LESKE 1 , ANTHEA M S CONNELL ${ }^{2}$, AND ROBERT KEHOE}

From the 'Department of Community and Preventive Medicine, State University of New York at Stony Brook, Stony Brook, NY 11794, USA, and the ${ }^{2}$ Department of Ophthalmology, Queen Elizabeth Hospital, Bridgetown, Barbados, West Indies

SUMMARY The prevalence of open-angle glaucoma is believed to be very high among West Indian blacks. To begin investigating the prevalence and risk factors for glaucoma and other eye diseases in Barbados, WI, a pilot study was conducted. The pilot project identified a stratified, random national sample of 300 persons over 35 years of age who were invited to participate in an ophthalmic examination and an interview. Of those contacted $89 \%$ were eligible and $95 \%$ of these agreed to participate. The overall glaucoma prevalence in the participants was $6 \%$; it was $13 \%$ among black and mixed persons over 54 years. Age related cataract, hypertension, and diabetes were frequent findings. Although the sample size of the pilot project is small, the results suggest a high prevalence of glaucoma in Barbados, a finding that merits further study.

Open-angle glaucoma is a major cause of visual impairment in black populations. ${ }^{1-6}$ While the prevalence of glaucoma in whites is relatively lowaround $1 \%$ or less at ages under 70 years, ${ }^{7-9}$ several studies suggest a much higher frequency in populations of African descent. ${ }^{2-6}$ Among US blacks the incidence and prevalence of blindness registration from glaucoma is eight times higher than in whites. ${ }^{1}$ A large difference in rates is reported for all sexes and all age groups, with a non-white/white ratio of $15: 1$ at ages 45-64 years. In addition these data show a younger age at blindness registration for blacks than whites and a more advanced stage of visual impairment, suggesting an earlier age at onset and a more severe course of disease. As reviewed elsewhere, ${ }^{1011}$ the available epidemiological data on risk factors are extremely limited, and the reasons for the high susceptibility of black populations to glaucoma remain unknown.

An unusually high glaucoma risk among West Indian blacks has been reported. ${ }^{412} 13$ In Barbados, WI, the disease is considered to be the major cause of blindness, presenting with advanced optic nerve damage at an early age ${ }^{12} 13$ (and personal communication from the ophthalmologists in Barbados). Medical treatment has limited effectiveness at this stage of the disease. To study adequately the glaucoma problem in Barbados epidemiological data are needed on the prevalence and risk factors for the disease in this population.

Correspondence to Dr M C Leske.
An additional obstacle to the development of effective programmes to prevent or control visual loss is that very little is known about the epidemiology of other eye diseases in black populations. Few studies have determined prevalence and risk factors for age related cataract, macular degeneration, or diabetic retinopathy in such populations. Clinical studies in Africa found a low frequency of maculopathy, ${ }^{14}{ }^{15}$ but a somewhat higher prevalence has been reported for US blacks than whites. ${ }^{16} \mathrm{High}$ prevalences of diabetic retinopathy ${ }^{17-19}$ and of diabetic retinopathy blindness in blacks have been reported ${ }^{20}$ as well as a higher cataract prevalence in US blacks than whites. ${ }^{16}$ Data on risk factors, however, are very limited.

As a first step toward obtaining epidemiological data on the prevalence and risk factors for glaucoma and other eye diseases in a black population a pilot project was undertaken. The pilot project was designed to assess the extent of population participation in such a study as well as to test the proposed data collection methods. This paper reports the findings of that pilot investigation.

\section{Material and methods}

The island of Barbados, which has over 250000 inhabitants in an area 21 miles long and 14 miles wide ( 34 by $23 \mathrm{~km}$ ), is one of the countries with the highest population density. ${ }^{2122}$ As described elsewhere, ${ }^{23}$ the pilot study was based on a stratified random sample of the adult population of Barbados; the sample was 


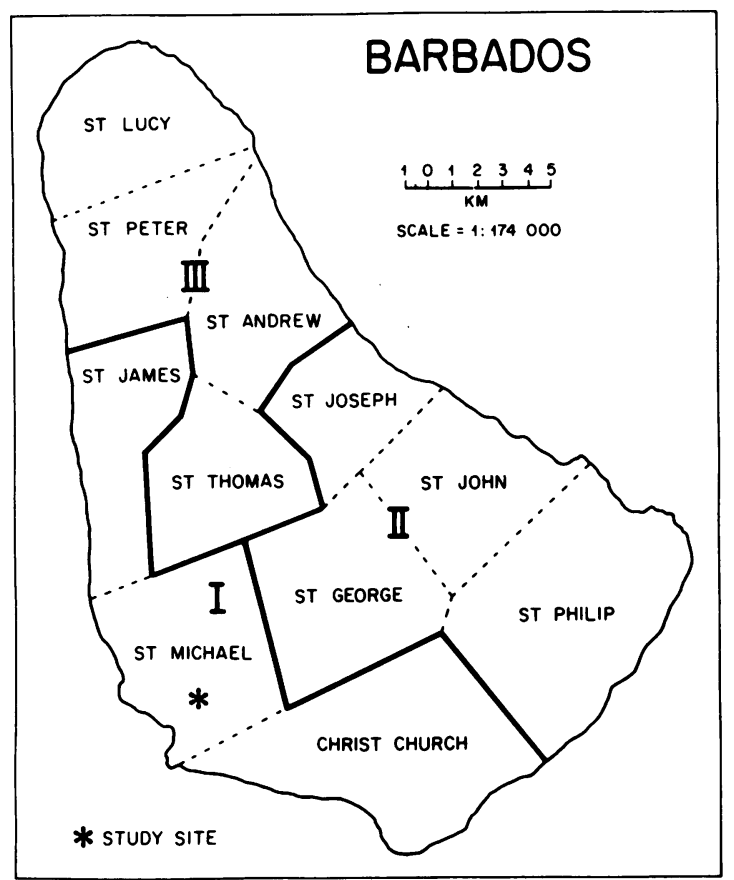

Fig. 1 Map of Barbados showing geographic regions in the sample.

drawn by randomly selecting 100 persons aged 35 years and over from each of three geographic strata. Stratum I included the highly urban regions of the country, with densities of 550-2500 persons per $\mathbf{~ k m}^{2}$; stratum II was an intermediate region with densities of 300-400 persons per $\mathrm{km}^{2}$; and stratum III included the less populated regions with densities of under 300 persons per $\mathrm{km}^{2}$ (Fig. 1). The sample was drawn from the Barbados National Register by the Barbados Statistical Service.

An invitation to participate in an eye examination at a Ministry of Health polyclinic was mailed to individuals included in the sample; telephone calls and/or home visits were made to schedule appointments. In the polyclinic all study participants had anthropometric and blood pressure measurements done, glycosuria screening, refraction and visual acuity testing with a Humphrey Automated Refractor 530, perimetry with a Humphrey Visual Field Analyzer 620, applantation tonometry, an interview to ascertain risk factors, fundus photography, and an examination by an ophthalmologist.

Screening for visual field defects used the 120-point 3-zone scheme of the Humphrey Analyzer. Whenever a screening field had 17 or more absolute or relative defects or eight or more defects clustered in one area, participants were retested with a central 30-2 threshold test. Such referral criteria have been reported as having a sensitivity of $95 \%$ and a specificity of $80 \%$ to detect glaucomatous visual field defects. $^{24}$ Diagnostic criteria for glaucoma were selected to include only established cases where the diagnosis was not in question. This definition would thus provide a minimum estimate of glaucoma prevalence. For the purposes of the pilot study definite glaucoma was diagnosed in the presence of intraocular pressure $>24 \mathrm{mmHg}$ and optic nerve damage, as shown by a definite abnormality of the disc on clinical examination (horizontal or vertical cup-disc ratios were $\geqslant 0.7$ ) and visual field defects confirmed by retesting. Participants who did not meet all the criteria for definite glaucoma diagnosis were considered as glaucoma suspects.

The prevalences of age related cataract, macular degeneration, and diabetic retinopathy were determined by clinical examination. The diagnosis of age related cataract was based on the presence of lens opacities with a visual acuity loss of 20/30 or worse in the absence of other apparent causes. To guide the examiner in diagnosing macular degeneration and diabetic retinopathy standard photographs were provided. 2526

The diagnosis of hypertension was based on a blood pressure $>160 / 95 \mathrm{mmHg}$ (average of two measurements) and/or a history of antihypertensive treatment. The diagnosis of diabetes was based on self-reported history. Since it was not possible to perform fasting blood glucose tests in the pilot study, all persons were screened for glycosuria and those found positive were referred for further examination. A $10 \%$ sample of persons with negative tests were asked to return for a fasting blood glucose test. This was done in an attempt to identify false negatives, since glycosuria screening has low sensitivity.

\section{Results}

The pilot study lasted three months, a time span which allowed contacting all but the last 48 persons in the sample. Of the 252 persons contacted $89.3 \%$ were eligible to participate and the rest were ineligible for the reasons shown in Table 1 . Of the eligible persons

Table 1 Eligibility to participate in the pilot study

\begin{tabular}{lc}
\hline & \multicolumn{2}{c}{ Number } \\
\hline Contacted & 252 \\
Eligible & \multicolumn{2}{c}{$225(89 \cdot 3 \%)$} \\
Could not participate & \multicolumn{2}{c}{$27(10 \cdot 7 \%)$} \\
$\quad$ Deceased & \multicolumn{2}{c}{6} \\
Seriously ill & \multicolumn{2}{c}{3} \\
Senile & 12 \\
Absent (overseas) & 48 \\
Not contacted & 300 \\
Total & 300 \\
\hline
\end{tabular}


$95 \%$ agreed to participate; there was no variation in participation by geographic region (Table 2). Data collection was completed for 193 persons in the time available. A comparison of the distribution by age, sex, and race (as recorded by interview) of the participants with that reported by the 1980 census shows very good agreement (Table 3 ). The pilot study examinees were therefore similar to the general population in those background variables.

According to the study definitions 12 persons (seven males, five females) were found to have definite open-angle glaucoma and 17 persons (seven males, 10 females) suspected glaucoma. All the cases of definite glaucoma were among persons of African descent, giving an overall prevalence of $6.9 \%$ in this group (Table 4). As regards age specific prevalences in black and mixed participants, 11 of the 12 cases were in persons $>54$ years, giving a prevalence of $12.8 \%$ in this age group. The prevalence of suspected glaucoma was about $9 \%$ (Table 4). Intraocular pressures over $21 \mathrm{mmHg}$ were found in $9 \%$ and $12 \%$ of right and left eyes respectively and tensions over 24 $\mathrm{mmHg}$ in $5 \%$ and $7 \%$.

The prevalences of age related cataract, macular degeneration, and diabetic retinopathy by clinical examination were $26 \%, 3 \%$, and $5 \%$ respectively (Table 5). A high prevalence of hypertension and diabetes was found in this population. Among black and mixed persons $>54$ years $59 \%$ had hypertension and $21 \%$ had been diagnosed as diabetics (Table 6); two-thirds of these diabetics had glycosuria.

\section{Discussion}

The pilot study results showed that the sampling method used was feasible, and most persons identified were eligible to participate (Table 1). The participation was high in all areas of the country, with an overall participation rate of $95 \%$ (Table 2). The age, sex, and race distributions of pilot study participants were comparable to those found in the 1980 census (Table 3 ), thus suggesting an adequately representative population for these variables. For all these reasons the effect of any possible biases related to non-participation is likely to be small.

The pilot study examination showed a high prevalence of open-angle glaucoma among Barbadians of African descent (Table 4), especially at older ages. The small number of people examined precludes any conclusions regarding the true prevalence of glaucoma and other eye diseases in the sample, since the number of persons with such conditions was small (Table 5). Hypertension was a frequent finding in the pilot study (Table 6), as in other black populations. The prevalence of self-reported diabetes was $13 \%$ (Table 6). Because the pilot study did not perform
Table 2 Participation of eligible persons by region

\begin{tabular}{lrrrr}
\hline & \multicolumn{2}{l}{ Region } & \\
\cline { 2 - 4 } & \multicolumn{1}{l}{$I$} & \multicolumn{1}{c}{ II } & III & Total \\
\hline Eligible to participate & 70 & 83 & 72 & 225 \\
$\quad$ Agreed & 67 & 78 & 68 & 213 \\
Refused & 3 & 5 & 4 & 12 \\
Percentage participation & 96 & 94 & 94 & 95 \\
\hline
\end{tabular}

Table 3 Percentage distribution of age, sex, and race in 193 pilot study participants versus the 1980 census

\begin{tabular}{lll}
\hline Age (years) & Participants (\%) & 1980 Census (\%) \\
\hline $35-44$ & 27 & 24 \\
$45-54$ & 25 & 25 \\
$55-64$ & 20 & 20 \\
$65-74$ & 17 & 20 \\
$75+$ & 12 & 11 \\
Sex & & \\
Females & 56 & 54 \\
Males & 44 & 46 \\
Race* & & \\
Black & 88 & 89 \\
Mixed & 5 & 6 \\
White & 5 & 4 \\
Other & 2 & 1 \\
\hline
\end{tabular}

*Excludes 5 persons with missing data.

Table 4 Age specific prevalence of definite and suspect glaucoma in black and mixed participants

\begin{tabular}{|c|c|c|c|c|c|}
\hline \multirow[t]{2}{*}{ Age group } & \multirow[b]{2}{*}{$n$} & \multicolumn{2}{|c|}{ Definite glaucoma } & \multicolumn{2}{|c|}{ Suspect glaucoma } \\
\hline & & $n$ & $\%$ & $n$ & $\%$ \\
\hline 35 & 45 & 1 & $2 \cdot 2$ & 2 & $4 \cdot 4$ \\
\hline $45-54$ & 43 & 0 & 0.0 & 3 & $7 \cdot 0$ \\
\hline $55-64$ & 34 & 3 & $8 \cdot 8$ & 4 & $11 \cdot 8$ \\
\hline $65-74$ & 32 & 6 & $18 \cdot 8\} 12 \cdot 8 \%$ & 3 & $9.412 .8 \%$ \\
\hline $75+$ & 20 & 2 & $10 \cdot 0$ & 4 & $20 \cdot 0$ \\
\hline Total (mean \%) & 174 & 12 & 6.9 & 16 & $9 \cdot 2$ \\
\hline
\end{tabular}

Table 5 Clinical diagnoses of cataract, macular degeneration, and diabetic retinopathy by age and race

\begin{tabular}{|c|c|c|c|c|c|c|c|}
\hline \multirow[t]{2}{*}{ Age, race } & \multirow[t]{2}{*}{$n$} & \multicolumn{2}{|c|}{ Cataract } & \multicolumn{2}{|c|}{$\begin{array}{l}\text { Macular } \\
\text { degeneration }\end{array}$} & \multicolumn{2}{|c|}{$\begin{array}{l}\text { Diabetic } \\
\text { retinopathy }\end{array}$} \\
\hline & & $n$ & $\%$ & $n$ & $\%$ & $n$ & $\%$ \\
\hline \multicolumn{8}{|c|}{ Black and mixed } \\
\hline $35-54$ years & 88 & 2 & 2 & 0 & 0 & 4 & 4 \\
\hline$>54$ years & 86 & 43 & 50 & 5 & 6 & 5 & 6 \\
\hline All & & 45 & 26 & 5 & 3 & 9 & 5 \\
\hline \multicolumn{8}{|c|}{ White and other } \\
\hline $35-54$ years & 7 & 0 & 0 & 0 & 0 & 0 & 0 \\
\hline$>54$ years & 7 & 4 & 57 & 1 & 14 & 0 & 0 \\
\hline All & & 4 & 29 & 1 & 7 & 0 & 0 \\
\hline \multicolumn{8}{|l|}{ All races } \\
\hline $35-54$ years & 95 & 2 & 2 & 0 & 0 & 4 & 4 \\
\hline$>54$ years & 93 & 47 & 50 & 6 & 6 & 5 & 5 \\
\hline All & & 49 & 26 & 6 & 3 & 9 & 5 \\
\hline
\end{tabular}


Table 6 Hypertension and self-reported diabetes by age and race

\begin{tabular}{|c|c|c|c|c|c|}
\hline \multirow[t]{2}{*}{ Age, race } & \multirow[t]{2}{*}{$n$} & \multicolumn{2}{|c|}{ Hypertension } & \multicolumn{2}{|c|}{ Diabetes history } \\
\hline & & $n$ & $\%$ & $n$ & $\%$ \\
\hline \multicolumn{6}{|c|}{ Black and mixed } \\
\hline $35-54$ & 88 & 25 & 28 & 4 & 4 \\
\hline$>54$ years & 86 & 51 & 59 & 18 & 21 \\
\hline All & & 76 & 42 & 22 & 13 \\
\hline \multicolumn{6}{|c|}{ White and other } \\
\hline $35-54$ years & 7 & 1 & 14 & $\mathbf{0}$ & $\mathbf{0}$ \\
\hline$>54$ years & 7 & 2 & 28 & 2 & 28 \\
\hline All & & 3 & 21 & 2 & 14 \\
\hline \multicolumn{6}{|l|}{ All races } \\
\hline $35-54$ years & 95 & 26 & 27 & 4 & 4 \\
\hline$>54$ years & 93 & 53 & 57 & 20 & 22 \\
\hline All & & 79 & 42 & 24 & 13 \\
\hline
\end{tabular}

blood testing for glucose on everyone, the true prevalence of diabetes is probably higher, a conclusion supporting the clinical impressions of a high diabetes frequency in this population.

The study reported here was a pilot investigation that was not designed to provide prevalence estimates for glaucoma or other conditions. The data suggest, however, that open-angle glaucoma is very frequent in Barbados (Table 4), a result that merits further study.

There is no clear explanation for an increased glaucoma risk in black populations. This increased susceptibility may be related to the somewhat higher intraocular pressure in blacks than whites. ${ }^{27}$ Although the reason for this increased intraocular pressure is not known, it might be at least partly related to the higher blood pressure, larger body size, and darker iris pigmentation of blacks than whites. All these variables have been associated positively with intraocular pressure in various population based studies. ${ }^{27-29}$ The differences in intraocular pressure between black and whites, however, are not large, and other variables probably contribute to their differences in glaucoma risk.

An increased severity of glaucoma among blacks could be due to a poor response to treatment in heavily pigmented eyes. While this clinical observation can explain a high risk of blindness among blacks who already have glaucoma, it does not account for an increased incidence of the disease. Other factors that could also explain an increased visual impairment from glaucoma among blacks include limitations in access to glaucoma treatment and/or poor compliance to prescribed treatment. Although these variables could affect disease severity, they would not be related to incidence.

In sum, despite the reported high glaucoma risk for blacks, the reasons for the increased risk are unknown. There is clearly a great need for investiga- tions which are designed to examine these issues and to provide data for blindness prevention programmes. The pilot study described here represents a first step towards implementing such an investigation.

The assistance of Dr Dorian Shilingford, Chief Medical Officer, Ministry of Health, Barbados, WI, is gratefully acknowledged. Mr William Griffith, Barbados Statistical Service, drew the sample, and Allergan-Humphrey loaned instrumentation; their assistance is similarly acknowledged.

Support was provided by grant RO3 EYO6945 from the National Eye Institute, National Institutes of Health, Bethesda, MD, USA.

\section{References}

1 Hiller R, Kahn HA. Blindness from glaucoma. Am J Ophthalmol 1975; 80: 62-9.

2 Cowan CL Jr, Worthen DM, Mason RP, Anduze AL. Glaucoma in blacks (Editorial). Arch Ophthalmol 1988; 106: 73\&-9.

3 Packer H, Deutsch AR, Deweese MK, et al. Frequency of glaucoma in three population groups. JAMA 1964; 188: 123-7.

4 Wallace J, Lovell HG. Glaucoma and intraocular pressure in Jamaica. Am J Ophthalmol 1969; 67: 93-100.

5 Clarke EE. A comparative analysis of the age distribution and types of primary glaucoma among populations of African and Caucasian origins. Ann Ophthalmol 1971; 3: 1055-71.

6 Martin MJ, Sommer A, Gold EB, Diamond EL. Race and primary open-angle glaucoma. Am J Ophthalmol 1985; 99: 383-7.

7 Hollows FC, Graham PA. Intraocular pressure, glaucoma, and glaucoma suspects in a defined population. $\mathrm{Br} J$ Ophthalmol 1966; 50: 570-86.

8 Leibowitz HM, Krueger DE, Maunder LR, et al.. The Framingham eye study monograph. Serv Ophthalmol 1980; 24 (suppl).

9 Bengtsson B. The prevalence of glaucoma. Br J Ophthalmol 1981; 65: 46-9.

10 Leske MC, Rosenthal J. Epidemiologic aspects of open-angle glaucoma. Am J Epidemiol 1979; 109: 250-72.

11 Leske MC. The epidemiology of open-angle glaucoma: a review. Am J Epidemiol 1983; 118: 166-91.

12 Connell AMS. State of eye care in areas of the Caribbean. Pan American Health Organization Report, 1983.

13 Connell AMS. Eye health: Progress report on the prevention of blindness. Georgetown, Guyana: CARICOM Secretariat, 1985.

14 Gregor Z, Joffe L. Senile macular changes in the black African. Br J Ophthalmol 1978; 62: 547-50.

15 Chumbley LC. Impressions of eye diseases among Rhodesian blacks in Mashonaland. S Afr Med J 1977; 52: 316-8.

16 Klein BE, Klein R. Cataracts and macular degeneration in older Americans. Arch Ophthalmol 1982; 100: 571-3.

17 Levin Y, Gelford M. Diabetic retinopathy in African patients. $S$ Afr Med J 1973; 47: 993-4.

18 Seftel HC, Walker ARP. Vascular disease in South African Bantu diabetics. Diabetologia 1966; 2: 286.

19 Tullock JA. Diabetes mellitus in the tropics. London: Livingstone, 1962.

20 US Department of Health, Education and Welfare. Statistics on blindness in the model reporting area 1969-1970. DHEW Publication No. NIH 73-427. Washington, DC: US GPO, 1973.

21 1980-81 Population census of the Commonwealth Caribbean, Barbados. CARICOM Secretariat, 1985: 2, 3.

22 Barbados-National Facts and Figures. Map and Visitors' Guide. Bridgetown: Ministry of Tourism and Environment, 1985.

23 Leske MC, Connell AMS. Design of a pilot study of glaucoma in Barbados. J Natl Med Assoc 1988; 80: 727-30.

24 Kosoko O, Sommer A, Auer C. Screening with automated perimetry using a threshold-related three-level algorithm. Ophthalmology 1986; 93: 882-6. 
25 Hyman LG, Lilienfeld AM, Ferris FL, Fine SL. Senile macular degeneration: a case-control study. Am J Epidemiol 1983; 118: 213-27.

26 Diabetic Retinopathy Study Research Group, Report 7. A modification of the Airlie House classification of diabetic retinopathy. Invest Ophthalmol Vis Sci 1981; 21: 210-26.

27 Hiller R, Sperduto RD, Krueger DE. Race, pigmentation and intraocular pressure. Am J Epidemiol 1982; 115: 674-83.
28 Leske MC, Podgor MJ. Intraocular pressure, cardiovascular risk variables, and visual field defects, Am J Epidemiol 1983; 118: 280-7.

29 Shiose $Y$. The aging effect on intraocular pressure in an apparently normal population. Arch Ophthalmol 1984; 102: 883-7.

Accepted for publication 4 August 1988. 